\title{
Flashbulb memories: Special, but not so special
}

\author{
SVEN-ÄKE CHRISTIANSON \\ University of Umeà, Umeá, Sweden
}

\begin{abstract}
This study deals with flashbulb memories associated with the assassination of the Swedish prime minister Olof Palme. A major goal of this research was to explore the consistency of such memories through comparison of the subjects' recollections on two different occasions, one year apart. The results obtained indicated that flashbulb events are accurately recalled in terms of a narrative conception of the concomitant circumstances of the event, but that the event descriptions are not consistent with respect to the specific details of these circumstances. It was concluded that the loss of information during one year contradicts the notion that flashbulb memories persist in absolute accuracy over time, as has been claimed in previous studies. Rather, these memories appear to be reconstructions based on residuals of the circumstances concomitant with the specific event (i.e., that of first hearing of the shocking news), and these memories follow the same pattern of recollection as does recollection of other autobiographical and laboratory-induced emotional events.
\end{abstract}

On the evening of February 28, 1986, as he and his wife were walking home from a movie theater in downtown Stockholm, the Swedish prime minister, Olof Palme, was shot and killed in cold blood. The event's devastating impact on Swedish citizens resembles the emotional trauma experienced by many Americans when they were first told of the assassination of John F. Kennedy. The main purpose in the present study was to investigate Swedish citizens' recollections of the circumstances in which they first heard the news of Palme's assassination, and, more specifically, to study the consistency of these memories over time.

Previous research has shown an impressive concordance in subjects' remembering of shocking national events such as assassinations (see, e.g., Brown \& Kulik, 1977; Colegrove, 1899; Pillemer, 1984; Winograd \& Killinger, 1983). Not only does such emotionally shocking news itself remain very well preserved in people's memories, so too do the subjects' memories of the circumstances under which they first heard the news: the informant, the location, the time, the nature of any ongoing activity, the subject's own clothing, the subject's own affect, and so forth. This detailed recall performance was referred to as flashbulb memory by Brown and Kulik (1977), who attributed it to a neuropsychological "now print" mechanism that is triggered when an event is emotionally arousing, surprising, and consequential, or when an event has great "biological significance." According to Brown and Kulik, this special memory mechanism preserves the

\footnotetext{
This research was supported by Grant F 158/87 from the Swedish Council for Research in the Humanities and Social Sciences. The research was completed while the author was a Visiting Fulbright Scholar at the University of Washington. The author is indebted to Mats Carlsson, Anita Fredriksson, Maria Nilsson, and Stefan Viktorsson for their invaluable help in conducting the research. Many thanks also to Eugene Winograd and one anonymous reviewer for their constructive comments on an earlier draft of this paper. Requests for reprints should be sent to Sven-Ảke Christianson, Department of Psychology, University of Umeå, Rådhusesplanaden 2, S-902 47 Umeả, Sweden.
}

whole event, including many irrelevant details, relatively indiscriminately. As Colegrove reported (1899), such vivid images seem to be easily recallable even after 33 years. Thus, although in many experimental and clinical studies on memory of emotionally traumatic events, recollection has been found impaired with respect to certain, especially peripheral or irrelevant details of the emotional events (e.g., Christianson \& Loftus, 1987, 1988; Clifford \& Scott, 1978; Deffenbacher, 1983), it seems that no one forgets the flashbulb memories. ${ }^{1}$

One may still ask, however, whether these vivid recollections really do remain unchanged in memory over time. Brown and Kulik's description of a flashbulb memory as a "photographic picture" would lead us to suspect that such memories are completely accurate, and that nothing is later lost or added to the pictorial memory of the scene in which a person finds him- or herself when the flashbulb is first fired. Once one has access to the "picture," one should thus have access to both important and unimportant details of the flashbulb occasion. An uncritical acceptance of such vivid descriptions of events from the distant past has been questioned by Neisser (1982), on the ground that the accuracy of flashbulb memories has never been verified. After providing some examples of complete fabrication in flashbulb memories, Neisser concludes: "Apparently flashbulbs can be just as wrong as other kinds of memories; they are not produced by a special quasiphotographic mechanism"' (p. 45). Further argument against a special flashbulb-memory mechanism has recently been presented by McCloskey, Wible, and Cohen (1988). In their evaluation of previous research on flashbulb memories, they conclude that there are no empirical or logical grounds for postulating a special mechanism for this type of memories. Instead, McCloskey et al. suggest that "flashbulb memories should be viewed as products of 'ordinary' memory mechanisms, and hence as phenomena that may offer insights into the nature of these mechanisms"' (McCloskey et al., 1988, p. 171). ${ }^{2}$ 
Nevertheless, despite the occasional criticism, it does seem that we have a robust phenomenon, referred to as flashbulb memory, in which some information is retained quite vividly from highly emotional public events. These memories are reported to persist with little subjectively experienced loss of perceptual clarity (see, e.g., Brown $\&$ Kulik, 1977). Still, from these subjective reports of flashbulb memories we cannot tell how accurate people really are in their descriptions of the flashbulb event and its concomitant circumstances. The possibility remains that the descriptions of the circumstances may be have been altered or fabricated without conscious awareness.

One way to verify the accuracy and consistency of flashbulb memories is to ask subjects a series of questions about their recollection of the circumstances in which they first heard the shocking news, and then ask the same questions again later on, in order to compare the coherence between the descriptions reported on the two occasions. This double assessment procedure was employed by Pillemer (1984) in a study of peoples' memories of the assassination attempt on President Reagan on March 30, 1981, and it was also used more recently by McCloskey et al. (1988), in a study of peoples' recollections of the circumstances in which they first learned of the explosion of the space shuttle Challenger on January 28, 1986. Pillemer questioned the subjects 1 month, and again 6 months, after the assassination attempt, and he concluded that memories of such an event are highly consistent over a 6-month interval. On the other hand, in the McCloskey et al. study, the subjects were questioned a few days after the explosion, and then again 9 months later; a considerable inconsistency was found between the responses given on the two occasions. These results suggest that flashbulb memories are subject to inaccuracy and deterioration.

Just a month after the Challenger tragedy, the citizens of Sweden experienced their own national trauma-the assassination of their prime minister. Sad as this event was, it did present a parallel opportunity to use the double assessment procedure. Swedish citizens were asked on two occasions, one year apart, to give the most detailed description possible of the circumstances in which they learned of Palme's death. The first interview was conducted on April 10-12, 1986, approximately 6 weeks after the assassination had taken place; the second interview occurred one year later, in April 1987. By comparing the two sets of responses collected in these interviews, we can assess the accuracy of the subjects' reports, which would not be the case if the subjects had been asked only once, as was the case in Brown and Kulik's study. Furthermore, by asking the subjects twice, one can also obtain empirical evidence about the memorial consistency in the subjects' reports of detailed information over time.

A major question asked in this study was whether a flashbulb type of recollection is a core memory that persists across time, or rather a reconstruction based on residuals of the circumstances of the flashbulb event. It was hypothesized that if subjects' recollections of how they were told the news of Palme's death are to be con- sidered flashbulb memories as they are defined by Brown and Kulik (1977), one might expect the subjects to recollect identical details of the circumstances on both test occasions. That is, consistent and accurate flashbulb memories are here defined in terms of a nonsignificant difference between recall responses in a 1986 test and a repeated test in 1987 . On the other hand, if these recollections are merely reconstructions, subjects might recall the gist (central details) of the main event and reconstruct a narrative conception based on this core recollection. If the latter hypothesis is true, then flashbulb memories are very much comparable to other, more private, autobiographical memories (see Rubin, 1982; Rubin \& Kozin, 1984), and also to well preserved central detail information found in studies of laboratory-induced emotionally traumatic events (e.g., Christianson, 1984; Christianson \& Loftus, 1987, 1988).

Since an intense emotional reaction to a flashbulb event has been claimed as one of the most important theoretical prerequisites for a flashbulb memory (see Brown \& Kulik, 1977; Pillemer, 1984; Schmidt \& Bohannon, 1988), one major shortcoming of the data presented in the McCloskey et al. (1988) and the Pillemer (1984) studies is the lack of evidence of intense affect in their respective subjects. In the Pillemer study, the average emotion and surprise ratings were only moderate (about 3 on a five-point scale)-hardly the strong emotional response claimed by Pillemer (1984), as well as Schmidt and Bohannon (1988), who used the Pillemer results in their defense of the "flashbulb-memory hypothesis." In the McCloskey et al. (1988) study, the subjects' emotional reactions were unfortunately not measured, which makes it difficult to determine the empirical and theoretical value of their evaluation of memory processes associated with "flashbulb" events as opposed to other, "ordinary," emotionally surprising events. The issue of affect (and related states of surprise and consequentiality) as a major predictor for flashbulb memories was specifically addressed in the present study. Thus, a second major goal was to investigate whether higher levels of emotion, surprise, or behavioral consequences would bring about higher accuracy in recollection of the circumstances of the first report of the news. According to Brown and $\mathrm{Ku}$ lik (1977), one should expect that subjects who experienced the highest level of emotional arousal and surprise, and whose behavior was most affected by the news, would be more accurate about recalling the circumstances in which the news was received than would subjects who were less affected by the news.

\section{METHOD}

\section{Subjects}

Forty subjects, 20 of them men and 20 of them women, living in Umeå, Sweden, were called on the telephone on April 10-12, 1986. They were asked to participate in "a survey about people's recall of the circumstances when they first heard about the assassination of Olof Palme." The subjects were selected at random from the Umea telephone book. Their age range was 19 to 70 years 
$(M=37.8, S D=13.9)$. Half of the subjects were below 40 years of age. The same subjects were unexpectedly called a second time between April 10 and May 3, 1987, for a repeat interview. At both interview sessions, the subjects were assured that their responses during the interview would be strictly confidential.

\section{The Questionnaire}

The questionnaire used on the two test occasions contained 14 items. Eleven of these were questions about memory information, and 3 were rating tasks. Because of the lack of specificity of the answers to 3 of the questions, it was decided to exempt these 3 questions from the subsequent analyses. The 8 remaining memory questions of specific interest in this paper are summarized in Table 1.

The first seven questions in this table concern memories of the circumstance when the subject first heard the news about the death of Olof Palme. The first five were based on the canonical categories that Brown and Kulik (1977) found to be typical of flashbulb memories. Two circumstance questions (Questions 6 and 7) were added to these original canonical category questions. The additional questions were included in order to test further the claims that recollections of the flashbulb memories portray the individual's own reactions and behavior at the time of the consequential event (Pillemer, 1984) and that these recollections are "very like a photograph that indiscriminately preserves the scene in which each of us found himself when the flashbulb was fired"' (Brown \& Kulik, 1977, p. 74). If these statements are empirically true, one should expect specific, detailed information-such as what clothing the subjects were wearing, or what their first thoughts were upon hearing the news-to be part of flashbulb memories.

One question concerning a personal control event was also included. This question (Question 8) asked the subject to describe, in as much detail as possible, his or her clearest memory from the Saturday just prior to the first interview. When the subject was contacted again, one year later, this memory event was referred to as "the event you described from the last Saturday before we called you the first time." Question 8 was not intended to measure memory for personal circumstances; it merely served to give an index of what the subjects tended to remember about an ordinary, salient event over one year's time.

\section{Procedure}

The $\mathbf{4 0}$ subjects were contacted over the telephone by four interviewers who interviewed 10 subjects each. The interviewers began each call by informing the subject about the purpose of the interview, and by assuring the subject of the confidentiality of the responses to be given. After this introductory information, each subject was asked the questions listed in Table 1. For each response, a confidence rating was made on a 3-point scale (1 indicated a "guess," 2 "fairly sure," and 3 "sure"). Following these seven

\section{Table 1}

Questions Concerning the Circumstances When the Subjects First Heard About the Assassination of Olof Palme, and One Question (Question 8) Concerning a Vivid Personal Memory From the Last Saturday Before the Interview in 1986

1. Describe in as much detail as possible how you heard the news about Olof Palme's death.

2. What was the exact time when you heard the news?

3. Describe in as much detail as possible where you were at the time you heard the news.

4. What were you occupied with when you heard the news?

5. Who were you with when you heard the news?

6. Describe in as much detail as possible the clothes you were wearing at the time you heard the news.

7. What was your first thought when you heard the news?

8. Describe in as much detail as possible your most vivid memory from last Saturday (April 5, 1986). questions, the subject was asked to rate on a scale from 0 to 10 how upsetting he or she found the news about Palme's death $(0=$ not upsetting; $10=$ extremely upsetting). The subject was then asked to rate on a scale from 0 to 5 how surprised he or she was by the news $(0=$ not at all; $5=$ very much). Moreover, the subject was also asked to judge on a scale from 0 to 10 to what extent the news caused an immediate change in ongoing activity ( $0=$ not at all; $10=$ a large change). The rating of behavioral consequences was regarded as a measure of the subject's attention to the course of events in the media during the next couple of hours after hearing the news.

After answering the questions about the circumstances and the personal control event, the subject was asked his or her age, as well as some other background information, and then thanked for participating in the interview. The subject was not informed at the time of the first interview that he or she would be contacted a second time I year later. All responses given by the subject were written down during the interview.

Between 52 and 54 weeks after the first interview session, the four interviewers attempted to contact the $\mathbf{4 0}$ subjects again for a repeat interview. The telephone call began with a reminder that the subject had participated in a telephone interview 1 year back. The subject was then asked if he or she remembered what the interview was about, and if he or she was willing to answer again the same questions that were asked in the first interview in 1986. If the subject agreed to participate in this repeat interview, the subject was given the same questions and rating tasks in the same order as in the interview in 1986. For the last question in the interview, the subject was asked to describe in as much detail as possible the personal event he or she had reported from the last Saturday before he or she was contacted in 1986.

\section{RESULTS}

When contacted the second time, all subjects remembered the purpose of the first interview, and 36 of them were willing to participate again. The four subjects who did not wish to participate in the second interview were accordingly excluded from all data analyses.

The proportions of subjects in the 1986 interview who were able to recall the circumstantial details called for by the questionnaire are presented in the left-hand column of Table 2. As can be seen from this table, a very high proportion of the subjects (over $90 \%$ ) successfully recalled the detailed information in Questions 1-5. These five questions correspond to the canonical categories of information that are typically used to study flashbulb memories. A somewhat lower proportion of the subjects were able to recall the circumstances mentioned in Questions 6 and 7 (i.e., their own clothing and first thoughts). However, even for this specific, detailed information, performance was quite high. The high overall level of recall for the idiosyncratic circumstances is consistent with the data of Brown and Kulik and others, and it thus may be concluded that the subjects' recollections illustrate the phenomenon that has been referred to in the literature as "flashbulb memory."

The proportion of subjects in 1986 who recalled a vivid personal event from the last Saturday before the interview (see Question 8) is close to the same level as the proportion who recalled the concomitant circumstances of first hearing the news about Palme. This personal event could 
Table 2

Proportions of Subjects $(P)$ Who Recalled the Circumstances on First Hearing the News of Olof Palme's Assassination and Means of the Subjects' Confidence Ratings (C)

\begin{tabular}{|c|c|c|c|c|c|}
\hline \multirow[b]{3}{*}{ Question } & & & \multicolumn{3}{|c|}{ Memory 1987} \\
\hline & \multicolumn{2}{|c|}{ Memory 1986} & \multicolumn{2}{|c|}{ Strict } & \multirow{2}{*}{$\frac{\text { Lenient }}{\mathrm{P}}$} \\
\hline & $\mathbf{P}$ & C & $\mathbf{P}$ & C & \\
\hline 1. How did you hear the news? & 1.00 & 3.00 & .72 & 2.72 & .92 \\
\hline 2. What exact time was it? & .92 & 2.19 & .25 & 1.71 & .86 \\
\hline 3. Where were you? & .97 & 3.00 & .72 & 2.77 & .89 \\
\hline 4. What were you occupied with? & .92 & 2.72 & .50 & 2.38 & .72 \\
\hline 5. Who were you with? & .94 & 2.88 & .83 & 2.79 & .92 \\
\hline 6. What clothes were you wearing? & .75 & 2.61 & .25 & 1.96 & .56 \\
\hline 7. Your first thought? & .83 & 2.84 & .44 & 2.52 & .72 \\
\hline 8. Memory from last Saturday? & .89 & 3.00 & .11 & 2.63 & .22 \\
\hline
\end{tabular}

Note-Values are given for the 1986 interview, and for the 1987 interview. Values for 1987 include both the strict and the lenient scoring procedures.

therefore be regarded as a personal control event in relation to the flashbulb circumstances, when the same questions were asked in the interview of 1987.

It was argued that the consistency of the subjects' flashbulb memories could be inferred from the differences between the 1986 and the 1987 detailed recall of circumstances. An extensive difference in recall of specific details would imply that flashbulb memories follow the same patterns of deterioration that have been observed for memories of other, more common, unexpected and emotional events, and that they should therefore not be considered as being produced by a neurological mechanism that is specifically activated only by certain highly consequential and shocking occurrences.

The responses given by the subjects in the 1987 interview were evaluated according to different recall criteria: a "strict" scoring criterion and a "lenient" scoring criterion. Correct recall according to the strict scoring criterion required that the responses given in the 1987 interview include exactly the same specific, detailed information (though not necessarily in the same wording) that was reported in the 1986 interview. For example, if the subject reported, "I heard the news at 7:55 a.m.," in the 1986 interview, she was scored as correct in the 1987 interview if " $7: 55$ " was reported accurately to the minute. In the lenient scoring, on the other hand, the 1987 response was coded correct (i.e., consistent with the 1986 response) if it comprised essentially the same information within a more general description-that is, if the response was less specific, or if particular details were omitted or changed, while still including the gist of the first response. For example, if the subject replied, "about 8:00 a.m.," to the time question, instead of "7:55," as had been recalled in the 1986 interview, the subject was given credit according to the lenient recall criterion. A response differing from the first answer by more than 1 hour, such as "about 9:00 a.m.," or a vague time, such as "in the morning," was not counted as correct.

Another example will help illustrate the strict scoring criterion, which required that the essential details remain the same between the two interviews, although the specific wording might change. One subject, in her 1986 response to the question, "How did you hear the news?" reported,
“Was asleep. Telephoned by my daughter." In 1987 she responded, "My daughter called and woke me up in the morning-she had heard on the radio that Olof Palme was murdered." She was scored as correct, according to the strict criterion. An example of a pair of responses to the above question that were scored as correct according to the lenient criterion is the following: "Radio-a male voice" (1986); "Radio-I don't remember if it was a male or female voice" (1987). Since the response did include the core information, but not the specific details, it was scored as correct according to the lenient, but not the strict, criterion. In this particular example, if "radio" had been omitted from the 1987 response, then that response would have been scored as incorrect according to the lenient criterion.

Further examples of responses that were scored as correct according to the strict versus lenient criteria are listed below. If the subject responded, "Sat on my bed," to the question, "Where were you?" in 1986, then the 1987 response, "I sat on my bed and watched TV," was scored as correct according to the strict criterion. The 1987 response "In my apartment-I don't remember specifically where," following the 1986 response "In bed, in my sleeping room," was scored as incorrect. As for the question about what the subjects were doing when they heard the news: following the 1986 response " $H a d$ just got up from bed, turned on the TV, and was waiting for 'Good Morning Sweden"' (a popular TV program shown on Saturdays in Sweden), the 1987 response "Had got up from bed, turned on the TV ... and was waiting for 'Good Morning Sweden"' was scored as correct according to the strict criterion, because it included the same particular details as did the first response. A failure to mention that the subject "... was waiting to see "Good Morning Sweden"' still would have been scored as correct on the lenient scale. For the subject to be scored correct according to the strict criterion for his or her response to the question "Who were you with?" the subject was required to give the name or the family status of the accompanying person or persons. For example, following a 1986 response, "With Marie," a 1987 response of "Marie" would be scored as correct on the strict scale, while a 1987 response of "Marie and John" would be 
scored as correct on the lenient scale only. 1987 responses of "alone," or, "John," however, would have been scored as incorrect on both scales. If the subject reported, "Pretty sure that I was wearing a red/white striped nightgown," to the question concerning what he or she was wearing, the same specific details were required in 1987 for correct strict scoring. According to the lenient criterion, simply reporting "nightgown" without mentioning the stripes and colors would have been correct. Other descriptions of clothing-for example, "bathrobe," or "undressed"- would have been considered incorrect. Finally, the 1987 response "It is a joke. It is a radio play" was scored as correct on the strict scale when compared with the 1986 response "A play, a joke." A 1987 response "I cannot believe it-it's not true. Horrible that this has happened in Sweden," was scored as correct on the lenient scale when compared with the initial 1986 response, "It must be a sick person-this could not happen in Sweden." The 1987 response "Not true. Coup d'état. Awful for Sweden" was considered inconsistent with the 1986 response "An unusually bad joke." Two raters compared the 1986 responses with the corresponding 1987 responses, and the interrater agreement was high for all questions.

The proportions of subjects who were correct in the 1987 interview (i.e., who reported the same information in the 1987 interview as they did in the 1986 interview), according to both the strict and the lenient scoring criteria, are shown in the right-hand column of Table 2. As can be seen from this table, the recall scores for all questions answered in the 1987 interview, according to the strict criterion, differ clearly from the recall scores of the 1986 interview. Regarding the lenient recall scores (see the right-most column of Table 2), the decrease in recall performance was somewhat lower-especially for four of the seven circumstances questions (Questions 1,2,3, and 5).

A comparison between the mean values for subjects' recall of the circumstances across questions for $1986(.91)$ and the mean recall score of $1987(.53)$, based on the strict criterion, indicates a considerable loss of circumstantial detail information. On the other hand, a comparison with the mean lenient recall score $(.80)$, while it does show a substantial decrease in accuracy, still evinces a performance level that is very high. This difference in recall of circumstances between strict and lenient scoring suggests that the subjects were able to recall the essence of the circumstances over time (as revealed by the lenient recall scores), but that they exhibited a considerable loss of detailed information associated with these circumstances (as revealed by the strict recall scores).

Memory for the personal (nonflashbulb) control event was scored as "correct" in 1986 if the subject was able to give a vivid detailed description of a single personal event from the Saturday just prior to the initial interview. The 1987 response was scored as correct according to the strict criterion if it described the same particular eventfor example, "Out shopping with my parents and my kids downtown" - and included the same detailed information, such as "I bought a blue/orange striped jacket, a t-shirt, and white pants." The 1987 response was scored as correct according to the lenient criterion if it included a general description of the same event, regardless of what specific details were mentioned. The 1987 response was scored as incorrect if the subject recalled a totally different event, or responded that he or she didn't remember the event he or she had reported the last time.

Given the recall level for the personal (nonflashbulb) event, the memory loss was extensive in the 1987 interview, irrespective of the scoring criterion used. Comparison of the proportions of subjects who recalled the circumstances in which they heard the news of the Palme assassination with the proportion of subjects who recalled their personal event from the last Saturday before the 1986 interview makes it apparent that the Palme-related circumstances were much better retained than the personal event.

The mean values of confidence ratings associated with the recall responses in both the 1986 and the 1987 interviews are presented in Table 2 . These values indicate that the subjects were less confident on every question in their 1987 responses, as compared with the confidence levels for the 1986 interview. An overall 2 (year) $\times 7$ (question) ANOVA carried out on the confidence data associated with the circumstances questions revealed significant main effects of year $\left[F(1,35)=35.9, M S_{\mathrm{e}}=0.551\right.$, $p<.001]$ and question $\left[F(6,210)=20.7, M S_{\mathrm{e}}=0.780\right.$, $p<.001]$, and a nonsignificant interaction. Thus, in line with the considerable decline in recollection of the circumstances in the 1987 test, it seems that the subjects were also less confident in their recall responses in the 1987 interview as compared with the 1986 interview.

Mean ratings given by the subjects with respect to how upset they became on first hearing the news were 7.47 and 7.75 for the 1986 and the 1987 interviews, respectively. Mean values for how surprised they were by the news were 4.50 and 4.39 for 1986 and 1987 , respectively. Two one-way ANOVAs conducted on these data revealed the differences to be nonsignificant. The correlations of these ratings across individuals in 1986 and 1987 for each of these two scales were 0.80 and 0.88 for emotionality and surprise, respectively. On the basis of these data, one can conclude that the subjects assigned high levels of surprise and emotional arousal to themselves when receiving the news, and that the recollection of these feelings is consistent over time. Mean ratings of behavioral consequences were 5.86 and 6.58 , in the 1986 and 1987 interviews, respectively. A one-way ANOVA conducted on these data revealed the difference to be statistically significant $\left[F(1,35)=4.2, M S_{\mathrm{e}}=2.189, p<.05\right]$. The correlation between ratings in 1986 and 1987 for this scale was 0.72 .

To analyze whether the levels of emotionality, surprise, or behavioral consequences were critical to recollection of the circumstances in which they were told of Palme's assassination, the subjects were divided into groups of those who had "high" or "low" ratings for these three factors. The categorizing of the individuals was based on the ratings for 1986 rather than the average of the subjects' ratings for 1986 and 1987. Even if the correlational 
analyses of the subjects' ratings for 1986 and 1987 indicated high correlations for each of the three rating scales, the initial rating in 1986 was closer in time to the event and therefore less likely to be contaminated. The first analysis to be reported concerns a comparison between subjects who were high or low in emotionality: "highly upset" corresponds to ratings higher than 7 on a 10-point scale $(n=19)$, and "less upset" corresponds to ratings equal to or less than $7(n=17)$. The top row of Table 3 presents mean values of recall performance and confidence ratings across questions for these two groups. The mean for idiosyncratic circumstances recalled in the 1986 interview shows that the subjects who were high in emotionality about the news performed at a somewhat higher level compared with the subjects who were low in emotionality. The values with both strict and lenient scoring also indicate a considerable decrease in memory performance between 1986 and 1987.

Two separate 2 (high vs. low emotionality) $\times 2$ (year) ANOVAs-one for strict, and one for lenient, recall scores-were carried out on these mean values across questions. For recall data based on a strict scoring criterion, the ANOVA revealed a significant main effect only of year $\left[F(1,34)=100.9, M S_{\mathrm{e}}=0.0246, p<.001\right]$. Similarly, the ANOVA for the lenient recall data revealed a significant main effect only of year $[F(1,34)=13.9$, $\left.M S_{\mathrm{e}}=0.0145, p<.001\right]$. (Two ANOVAs were also conducted in which subjects with ratings higher than 9 on the emotionality scale were compared with subjects with ratings less than 6 . The results from these additional analyses-one for strict and one for lenient recall scoresexhibited the same effects as presented above.) A parallel ANOVA, carried out on the mean confidence ratings for these data, revealed a significant effect only of year $\left[F(1,34)=20.6, M S_{\mathrm{e}}=0.122, p<.001\right]$.

Separate analyses were also done to investigate possible effects of surprise on recollection of the circumstances. In these analyses, the subjects who exhibited a high level of surprise (ratings higher than 4 on a 5-point scale, $n=28$ ) were compared with the subjects who exhibited a somewhat lower level of surprise (ratings equal to or less than $4, n=8$ ). The middle row of Table 3 presents the mean recall scores for the high and the low group in the 1986 and 1987 interviews. An inspection of these values suggests that highly surprised subjects are superior to the less surprised subjects in recall of the circumstances. This difference between subjects can be seen in both the 1986 and the 1987 testing, for both strict and lenient recall scores. Two separate 2 (surprise) $\times 2$ (year) ANOVAs were carried out on the mean values across questionsone for strict, and one for lenient data. The ANOVA based on the strict recall scores revealed a significant main effect of year $\left[F(1,34)=64.2, M S_{\mathrm{e}}=0.0244, p<.001\right]$. No other effects were statistically significant. The ANOVA conducted on the lenient data showed significant main effects of year $\left[F(1,34)=12.3, M S_{\mathrm{e}}=0.144, p<.01\right]$ and of surprise $\left[F(1,34)=6.7, M S_{\mathrm{e}}=0.0433, p<.05\right]$, and a nonsignificant interaction.

The subjects who had high ratings of surprise and who displayed a higher recall performance (lenient values) were not, however, more confident in their recall responses, as compared with the subjects who were less surprised and less accurate in recollection. A 2 (group) $\times 2$ (year) ANOVA conducted on these mean ratings revealed a statistically significant main effect only of year $\left[F(1,34)=11.6, M S_{\mathrm{e}}=0.127, p<.001\right]$. No other effects were significant.

Comparisons between subjects for which the news caused extensive behavioral consequences (ratings larger than 5 , $n=19$ ) and subjects who rated a somewhat lower change in action (ratings equal to or less than $5, n=17$ ), did not show any marked differences in recollection of the circumstances. A 2 (consequentiality) $\times 2$ (year) ANOVA on strict recall scores showed a significant main effect only of year $\left[F(1,34)=103.3, M S_{\mathrm{e}}=0.0242, p<.001\right]$. A parallel $2 \times 2$ ANOVA on the lenient scores showed the same significant effect of year $[F(1,34)=14.8$, $\left.M S_{\mathrm{e}}=0.0139, p<.001\right]$. A separate ANOVA of the confidence ratings also revealed a significant effect of year $\left[F(1,34)=21.7, M S_{\mathrm{e}}=0.0120, p<.001\right] .^{3}$

Separate ANOVAs including sex or age as factors were also conducted. The results from these analyses did not reveal any significant main effects or interactions with these variables.

\section{DISCUSSION}

This study was based upon 36 people's recollections of the circumstances in which they first heard about the assassination of the Swedish prime minister, Olof Palme.

Table 3

Mean Proportion Recall $(P)$ of the Circumstances on First Hearing the News of Olof Palme's Assassination and Means of the Subjects' Confidence Ratings $(C)$ Across Questions

\begin{tabular}{|c|c|c|c|c|c|c|c|c|c|c|}
\hline & & & & & \multicolumn{6}{|c|}{ Recall 1987} \\
\hline & \multicolumn{4}{|c|}{ Recall 1986} & \multicolumn{4}{|c|}{ Strict } & \multicolumn{2}{|c|}{ Lenient } \\
\hline & \multicolumn{2}{|c|}{ Low } & \multicolumn{2}{|c|}{ High } & \multicolumn{2}{|c|}{ Low } & \multicolumn{2}{|c|}{ High } & \multirow{2}{*}{$\frac{\text { Low }}{\mathrm{P}}$} & \multirow{2}{*}{$\frac{\text { High }}{\mathrm{P}}$} \\
\hline & $\mathbf{P}$ & C & $\mathbf{P}$ & $\mathrm{C}$ & $\mathbf{P}$ & $\mathrm{C}$ & $\mathbf{P}$ & $\mathrm{C}$ & & \\
\hline Emotionality & .88 & 2.65 & .93 & 2.85 & .53 & 2.39 & .53 & 2.36 & .79 & .81 \\
\hline Surprise & .80 & 2.64 & .94 & 2.79 & .48 & 2.36 & .55 & 2.38 & .66 & .84 \\
\hline Behavioral consequence & .89 & 2.68 & .92 & 2.83 & .55 & 2.42 & .52 & 2.33 & .75 & .85 \\
\hline
\end{tabular}

Note-Values are given for the 1986 interview, and for the 1987 interview. Values for 1987 include both the strict and the lenient scoring procedures. Subjects are divided into groups that were high $(\mathrm{H})$ or low $(\mathrm{L})$ in emotionality, or behavioral consequence. 
The responses, first collected 6 weeks and again 1 year after the assassination, showed that the news was highly surprising, emotionally arousing, and consequential to the Swedish people. When the subjects were interviewed the first time, there was a high overall level of recall of the circumstances in which they learned the news. On the basis of these findings, one can argue that we are dealing with the same type of memories that have been referred to as "flashbulb memories" in the previous literature (e.g., Brown \& Kulik, 1977).

Furthermore, it was found that the "flashbulb" circumstances were more accurately recalled than the salient personal control event (i.e., the "memory from the last Saturday ..."), when the subjects were questioned in the repeated interview. This result indicates a higher level of recall for a highly emotional and surprising event, including many of its specific details, as compared with the "vivid" memory of an everyday event. However, caution must be taken in comparing these two events, since the flashbulb questions concern circumstances surrounding a known event, while the personal event question does not. It is possible that the subjects simply didn't remember what event they had reported from that particular Saturday one year back, and that they might have been able to give descriptions of specific circumstances if they had first been given a short description of the event they reported in 1986. Certainly the method of measuring the control event in the present study was not perfect. The 1987 results indicate the severe difficulties involved in gaining access to memories of ordinary events. Thus, future research could increase the compatibility between ordinary and flashbulb events by providing better cues for the former-if such events are used as controls for flashbulb events.

The difference between the recall scores of the 1986 and the 1987 responses indicated that the subjects' recollections of the circumstances were significantly reduced over one year's time, according to both a strict and a lenient scoring criterion. That is, the recollections of 1987 did not include the same detail information that was recalled in 1986.

These results contradict the theory of a neurophysiologically based "now print" mechanism (see Brown \& Kulik, 1977), whereby the scene in which people find themselves when receiving shocking news will persist indiscriminately and will be recollected like a "photographic" picture. Rather, in line with Neisser (1982), the present study suggests that the detailed content in flashbulb memories is reconstructed from recollections of the gist of the event. This reconstruction is presumably made according to a narrative conception of the crucial event and its concomitant circumstances, and it is the structure of this narrative conception that accounts for the canonical form of flashbulb memories (see Neisser, 1982, p. 47). The term reconstruction, as it is used in this context, implies that the subject might remember, for example, merely that he or she first heard the news of Palme's assassination in the morning - as was true for most Swed- ish people - and that on the basis of the subject's own usual morning habits, he or she would be able to make inferences about the specific circumstances of the morning in question (see Loftus \& Loftus, 1980; Neisser, 1982; Nilsson \& Shaps, 1981, for a further discussion of the concept of reconstruction).

It is important in a paper such as this to raise the additional possibility that the subjects' initial reports in 1986 may not have been truthful or accurate observations of the original situation when the news was first delivered. In fact, work by Loftus (1979) has shown that people's recollections are often easily influenced by postevent information. Moreover, as Winograd and Killinger argued in their study of childhood memories of public events, "There is an important sense in which no memory is false. If the information is part of one's cognitive system, its presence needs to be explained.... But these reports may faithfully reflect the current state of the cognitive structures underlying memory reports; that is, memory is among other things, a belief system" (Winograd \& Killinger, 1983, pp. 420-421). Thus, in considering the observations made in this study, along with the earlier findings reported by Loftus (1979) and Winograd and Killinger (1983), one cannot take for granted that people really report what was originally encoded.

Suppose that recall of the circumstances is the result of a reconstructive process. Since, unlike in laboratory studies, there is no way of knowing what the subjects in this study were actually doing, wearing, etc., when they heard the news of Palme's death, the initial recalls (i.e., 6 weeks after the assassination) may very well be reconstructive, and presumably they may contain some erroneous information-some plausible information that fits with the most recallable details. An important question is, what proportion of the initial memories or what particular details are of this sort? While a second attempt to remember the circumstances is likely to produce the same output for some core elements, many of the plausible constructions might change. A fuller understanding of what caused the difference in performance levels between the first and the second recall attempts might have been attained by way of additional retesting at short test intervals. Such retests would provide one way of discovering whether the type of response changes seen in this study are caused by actual forgetting, or whether they are caused by changes in reconstructions. Unfortunately, this study did not include a baseline measurement of how much change might have occurred in a second test given shortly after the first interview (for example, the following week). If such data had been collected and had revealed either no difference in responses or a substantial change, we would be better able to decide whether all details are automatically and accurately registered initially and then deteriorate with the passage of a year's time, or, alternatively, whether these changes are mere reconstructions from the very beginning. Regardless of whether reconstruction or forgetting caused the decrement in memory performance over time seen in the present study, the decrement itself 
is evidence against a special flashbulb mechanism. After this research was completed, it was learned that the same conclusion was reached by McCloskey et al. (1988).

This study also included an investigation of the effect of emotionality, surprise, and behavioral consequences on the recall of flashbulb circumstances. It was found that, when told the news, the subjects generally experienced very high levels of emotionality, surprise, and behavioral consequence (i.e., change in ongoing activity). Data from three fine-grained analyses, carried out to study the effects of these factors on recollection, revealed similar tendencies for all three factors. That is, high ratings for emotionality, surprise, or changes in action seem to be associated with better recall of flashbulb circumstances. However, statistical significance was obtained only for surprise, with the lenient criterion: the subjects who rated high in surprise showed a higher level of overall recall. The lack of a significant effect for the other factors is most probably explained by ceiling effects-that is, almost all subjects were highly affected by the news, and it was therefore not possible to really compare groups in terms of "high" or "low" emotionality, surprise, or behavioral consequence. Thus, like Schmidt and Bohannon (1988), one can argue that the flashbulb type of memory may vary continuously with increasing levels of affect. However, instead of claiming that a special flashbulb mechanism is involved during states of high affect in flashbulb situations-as, for example, Schmidt and Bohannon would claim-it seems more natural to interpret the flashbulb memory phenomenon in terms of the same mechanisms as are believed to be involved in other experiences of intense, emotionally arousing events (see Christianson, 1984; Christianson \& Loftus, 1987, 1988; Christianson \& Nilsson, 1989; Rubin \& Kozin, 1984). (See also the discussion below of central and peripheral details.)

What aspects are remembered in "flashbulb memories"? If we look at the lenient recall scores, it seems that some core information was less vulnerable to memory loss, whereas the more specific, detailed information suffered somewhat more during 1 year (cf. the strict recall scores). A decreased accuracy with respect to specific details is further reflected in this study in the lower proportion of subjects able to recall the more specific circumstantial details (cf. the two questions about clothing and first thoughts), as compared with the regular canonical detailed information. This pattern of results regarding the content and awareness of flashbulb memories parallels in some respects recent findings reported for recall of central and peripheral detail information of laboratory-induced emotional events (see, e.g., Christianson, 1984; Christianson \& Loftus, 1987, 1988). Two studies (e.g., Christianson \& Loftus, 1987, 1988) have specifically shown that traumatic pictures are less well retained with respect to the peripheral details of the pictures, but that central details are very well retained. Moreover, it has also been found that the gist (central details) of the emotional event (i.e., the sum of the central aspects of the event) is well retained in memory over longer retention intervals, whereas a considerable loss may be seen for peripheral aspects of the same event. The "flashbulb memories" reported in this study mirror these laboratory findings in the sense that people tend to remember the gist (central details) of an emotionally provoking event while experiencing a considerable decrease in performance level for peripheral details or very specific circumstances of the event. One can therefore agree with Rubin and Kozin's (1984) conclusion that almost all autobiographical memories are of flashbulb clarity soon after the occurrence, but that loss of clarity and detail over time seems to be less for some events than for others. This describes reasonably well the memory effects reported for laboratory-induced traumatic events and for the natural traumatic event reported in the present.

In conclusion, the results of this study indicate that "flashbulb memories" are not consistent over time or immune to deterioration with respect to the specific circumstances of the flashbulb event. It is therefore concluded that flashbulb memories do not constitute a separate category of autobiographical memory. Instead, these memories are merely reconstructions that follow the same pattern of recollection as has been demonstrated in laboratory studies involving highly emotional events. That is, central detailed information seems to be well preserved, whereas peripheral, more irrelevant information is less accurately retained and less consistent over time.

\section{REFERENCES}

Brown, R., \& Kuluk, J. (1977). Flashbulb memories. Cognition, 5, 73-99.

Christianson, S.-Á. (1984). The relationship between induced emotional arousal and amnesia. Scandinavian Joumal of Psychology, 25, 147-160.

Christianson, S.-À., \& LofTus, E. F. (1987). Memory for traumatic events. Applied Cognitive Psychology, 1, 225-239.

Christianson, S.-A., \& LofTus, E. F. (1989). Remembering emotional events: The fate of detailed information. Manuscript submitted for publication.

Christianson, S.-Ȧ., \& Nilsson, L.-G. (1989). Hysterical amnesia: A case of aversively motivated isolation of memory. In T. Archer \& L.-G. Nilsson (Eds.), Aversion, avoidance, and anxiety: Perspectives on aversively motivated behavior (pp. 311-322). Hillsdale, NJ: Erlbaum.

CuFford, B. R., \& ScoTt, J. (1978). Individual and situational factors in eyewitness testimony. Joumal of Applied Psychology, 63, 352-359.

Cohen, N. J., McCloskey, M., \& Wible, C. G. (1988). There is still no case for a flashbulb-memory mechanism: Reply to Schmidt and Bohannon. Journal of Experimental Psychology: General, 117, 336-338.

Colegrove, F. W. (1899). Individual memories. American Journal of Psychology, 10, 228-255.

DEFFENBACHER, K. A. (1983). The influence of arousal on reliability of testimony. In S. M. A. Lloyd-Bostock \& B. R. Clifford (Eds.), Evaluating witness evidence (pp. 235-251). New York: Wiley.

LofTUS, E. F. (1979). Eyewitness testimony. London: Harvard University Press.

LoFTUS, E. F., AND LofTUs, G. R. (1980). On the permanence of stored information in the human brain. American Psychologist, 35, 409-420.

MCCloskey, M., Wible, C. G., \& Cohen, N. J. (1988). Is there a special flashbulb-memory mechanism? Journal of Experimental Psychology: General, 117, 171-181. 
Neisser, U. (1982). Snapshots or benchmarks? In U. Neisser (Ed.), Memory observed (pp. 43-48). San Francisco: Freeman.

NiLsSON, L.-G., \& SHAPS, L. A. (1981). A reconstructive-processing interpretation of the recognition failure phenomenon. Acta Psychologica, 47, 25-37.

Pillemer, D. B. (1984). Flashbulb memories of the assassination attempt on President Reagan. Cognition, 16, 63-80.

RUBIN, D. C. (1982). On the retention function for autobiographical memory. Journal of Verbal Learning \& Verbal Behavior, 21, 21-38.

Rubin, D. C., KozIN, M. (1984). Vivid memories. Cognition, 16, 81-95.

SCHMIDT, S. R., \& BoHANNON, J. N. III (1988). In defense of the flashbulb-memory hypothesis: A comment on McCloskey, Wible, and Cohen (1988). Journal of Experimental Psychology: General, 117, 332-335.

WinOgRAD, E., \& Killinger, W. A., JR. (1983). Relating age at encoding in early childhood to adult recall: Development of flashbulb memories. Joumal of Experimental Psychology: General, 112, 413-422.

\section{NOTES}

1. The term flashbulb memories is used in a functional sense in this paper, without referring to a special category of memories or a specific flashbulb memory mechanism.
2. In a comment on the McCloskey, Wible, and Cohen (1988) study, Schmidt and Bohannon (1988) have argued that McCloskey's conclusions concerning evidence of the nonexistence of a flashbulb mechanism sufficient to reject the existence of a special flashbulb mechanism was premature. In reply, Cohen, McCloskey, and Wible (1988) question the logic of such a comment: "While apparently conceding that there is no clear evidence for a special mechanism, they (Schmidt \& Bohannon) argued that 'conclusions concerning the existence of a flashbulb memory mechanism are premature"' (p. 336). Cohen et al. see things differently -that is, they claim that the burden of proof rests with those arguing for a special mechanism, and that in the absence of clear evidence that flashbulb memories cannot be explained in terms of ordinary memory mechanisms, the view that there is no special flashbulb mechanism should be preferred.

3. In addition to the ANOVAs, correlations were also made between the memory data and ratings of emotionality, surprise, and consequentiality. The results from these correlation analyses were, however, less informative than were the median splits, because of the skewed distribution of the subjects' ratings on these three variables.
(Manuscript received May 13, 1988 revision accepted for publication October 31,1988 .)

\section{Announcement}

\section{4th Annual Boston University Conference on Language Development October 13, 14, and 15, 1989}

The 14th Annual Boston University Conference on Language Development is scheduled for October 13, 14, and 15, 1989. The keynote speaker will be William Labov of the University of Pennsylvania.

Sessions will focus on the following central themes: American Sign Language; Literacy in Theory and in Practice (literacy and ideology, literacy at school, in the humanities, in the workplace, minorities' interpretation, sociocultural approaches); Language Acquisition (theories of evidence, neural maturation); First Language Acquisition (including principles and parameters, acquisition of LF, irregular phenomena, phonology); and Second Language Acquisition (including age factors, parameter setting, and sociocultural factors).

For further information and a preliminary program, please contact Conference Committee, Conference on Language Development, Boston University, 605 Commonwealth Ave., Boston, MA 02215 (telephone: 617-353-3085) 